\title{
Current role of microwave ablation in the treatment of small hepatocellular carcinomas
}

\author{
Natalie Lucchina a , Dimitrios Tsetis ${ }^{b}$, Anna Maria lerardia, Francesca Giorlando ${ }^{a}$, Edoardo Macchia, \\ Elias Kehagias ${ }^{b}$, Ejona Duka ${ }^{a}$, Federico Fontanaa ${ }^{a}$, Lorenzo Livraghic, Gianpaolo Carrafiellod \\ Insubria University, Varese, Italy; University Hospital of Heraklion, Crete, Greece; University of Milan, Milan, Italy
}

\begin{abstract}
Percutaneous radiofrequency ablation (RFA) can be as effective as surgical resection in terms of overall survival and recurrence-free survival rates in patients with small hepatocellular carcinoma (HCC). Effectiveness of RFA is adversely influenced by heat-sink effect. Other ablative therapies could be considered for larger tumors or for tumors located near the vessels. In this regard, recent improvements in microwave energy delivery systems seem to open interesting perspectives to percutaneous ablation, which could become the ablation technique of choice in the near future. Microwave ablation (MWA) has the advantages of possessing a higher thermal efficiency. It has high efficacy in coagulating blood vessels and is a relatively fast procedure. The time required for ablation is short and the shape of necrosis is elliptical with the older systems and spherical with the new one. There is no heat-sink effect and it can be used to ablate tumors adjacent to major vessels. These factors yield a large ablation volume, and result in good local control and fewer complications. This review highlights the most relevant updates on MWA in the treatment of small $(<3 \mathrm{~cm})$ HCC. Furthermore, we discuss the possibility of MWA as the first ablative choice, at least in selected cases.
\end{abstract}

Keywords Microwave ablation, small hepatocellular carcinoma, radiofrequency ablation

Ann Gastroenterol 2016; 29 (4): 1-6

\section{Introduction}

In the past decade the diagnosis of HCC has changed from being a death sentence to a manageable disease. The semiannual surveillance of high-risk population using ultrasound permits to diagnose at an early stage, at which curative treatments can be employed [1]. Surgical resection is currently considered to be the definitive treatment for patients who have an optimal profile, as defined by the Barcelona clinic liver cancer (BCLC) staging system [1]. On the other hand, for patients with early-

Departments of ${ }^{a}$ Radiology Insubria University, Varese, Italy (Natalie Lucchina, Anna Maria Ierardi, Francesca Giorlando, Edoardo Macchi, Ejona Duka, Federico Fontana); ${ }^{b}$ Radiology, University Hospital of Heraklion, Crete, Greece (Dimitrios Tsetis, Elias Kehagias); 'Surgical Sciences, University of Insubria, Varese, Italy (Lorenzo Livraghi); dDiagnostic and Interventional Radiology, San Paolo Hospital, Department of Health Sciences, University of Milan, Italy

Conflict of Interest: None

Correspondence to: Gianpaolo Carrafiello, University of Milan, Diagnostic and Interventional Radiology, San Paolo Hospital, Department of Health Sciences, Via A. di Rudinì 8, 20142 Milan, Italy, Tel.: +39 02 81841, e-mail: gcarraf@gmail.com

Received 16 February 2016; accepted 29 May 2016; published online 24 June 2016

DOI: http://dx.doi.org/10.20524/aog.2016.0066 stage HCC who are not candidates for surgery, percutaneous local ablation (PLA) is currently recommended as the best therapeutic alternative $[2,3]$.

Indications for PLA include: HCC in BCLC stage A with Child-Pugh class A/B cirrhosis; an Eastern Cooperative Oncology Group (ECOG) performance status of $0-1$; tumor dimensions $<5 \mathrm{~cm}$ (ideally $<3 \mathrm{~cm}$ ); focal nodular lesion; and solitary or multiple lesions. Contraindications include: presence of vascular invasion; extrahepatic metastatic disease; sepsis; severe debilitation; Child-Pugh class C cirrhosis; and uncorrectable coagulopathy [4].

RFA has been the most widely investigated modality of percutaneous ablation therapy for unresectable HCCs. Numerous large series have shown that RFA is safe, with minimal morbidity and mortality [5]. Some investigators have suggested that tumor location is closely associated with the risk of major complications [6]. In fact lesions located close to gallbladder, liver capsule and diaphragm are associated with a higher risk of complications [7]. RFA of nodules adjacent to large vessels may also often result in incomplete ablation because of the "heat-sink" effect. Overall, it is believed that $10-25 \%$ of patients with HCC may not be eligible for RFA [8].

MWA is a relatively new technique that can be applied to different types of tumors and offers all the benefits of RFA as well as some substantial advantages. These include a larger volume of cellular necrosis, reduction in procedure times, greater temperatures delivered to the target lesion, the 
possibility of using multiple antennae simultaneously, efficacy on lesions with a cystic component and/or in proximity to vascular structures $>3 \mathrm{~mm}$ in diameter with a reduction in the heat-sink effect, and less intra-procedural pain [9-11]. Promising results of MWA for HCC have been demonstrated in several studies $[12,13]$.

The aim of this review was to analyze current results of MWA in the treatment of small $(<3 \mathrm{~cm}) \mathrm{HCC}$ and to determine if MWA can be applied as first-choice treatment in specific cases.

\section{Materials and methods}

\section{Study selection}

A systematic literature search was performed in PubMed, with the syntax microwave OR MWA, AND small hepatic tumor OR small HCC, OR small hepatocellular carcinoma, OR small liver cancer, including only studies published in English from January 2005 to December 2015. All titles and abstracts of identified studies in the initial search were screened to select those reporting ablation of HCC in patients with unresectable disease.

On the basis of dimension and number of nodules, the BCLC staging system divides HCC in stage 0 , very early; A, early; B, intermediate; C, advanced; and D, terminal [1]. For the present review we considered only early stages 0 and $A$, in particular patients with no more than 3 nodules with a diameter of $\leq 3 \mathrm{~cm}$. Some studies reported as small HCC, tumors having a diameter of $<5 \mathrm{~cm}$. In these studies we tried, when possible, to select only the patients having HCC nodules with a diameter of $\leq 3 \mathrm{~cm}$, thus reporting only results for the extrapolated cases. Studies in which results for lesions with a diameter of $<3 \mathrm{~cm}$ could not be extrapolated were not taken into consideration. We also excluded studies in which tumors were treated simultaneously with PLA and transarterial embolization. We identified additional studies through manual search of the primary studies references, review articles, and key journals. We excluded papers that included data reported previously.

The primary endpoint was to investigate safety and complications of this technique. Secondary endpoint was to present the current status of MWA in the treatment of small HCCs with the intention, if possible, to correlate incomplete ablation or recurrence with specific factors (location, technical problem, etc.). The following variables were extracted, where available, from the included articles: number of patients; mean age of patients; tumor location; complications; mean follow up and survival; or treatment response. Median survival was calculated.

\section{MWA}

Six studies, involving a total of 384 patients with HCC nodules treated with MWA, fulfilled the eligibility criteria [14-19] (Table 1). At least 471 nodules had a diameter $<3 \mathrm{~cm}$. The mean age of patients was 59.5 years old.

Initial complete response was achieved in $97.67 \%$ of the treated nodules. Ablation was classified as "complete" when no areas of enhancement were seen within or at the periphery of the ablation zone at the dynamic triphasic CT scan performed after the procedure. The mean follow up time was 27 months. The median overall survival time was $95.85 \%$ at 1 year and $68.86 \%$ at 3 years. Two studies $[14,16]$ reported an overall survival rate of $78 \%$ and $62.5 \%$ at 5 years. Overall survival was in the range of $89-100 \%$ at 1 year and in the range of $49-80 \%$ at 3 years.

Tumor size was one of the most important prognostic factors in determining survival rate, but no difference in survival was reported between nodules $<2.5 \mathrm{~cm}$ and $<4 \mathrm{~cm}$ in the study of Liang et al [16]. The most probable explanation may be that the coagulated area of MWA was large enough to envelop HCCs smaller than or equal to $4.0 \mathrm{~cm}$ in maximum diameter, and a tumor-free margin of at least $5.0 \mathrm{~mm}$ could be obtained in one stroke [16].

Complications related to the procedure included three major incidents reported by Ding et al [18]: One patient showed symptoms of shortness of breath and incomplete intestinal obstruction 13 months after MWA. The patient was diagnosed with right diaphragmatic hernia and massive right pleural effusion by contrast-enhanced CT and ultrasound. The patient was treated conservatively and a thoracic drainage tube was placed. Symptoms improved after 1 week and the drainage tube was removed. Two Child-Pugh class B patients presented with liver decompensation after treatment. Liver function of one of the two patients worsened and he died two months post-ablation. The other patient's liver function improved after intense liver protective treatment. Ohmoto et al [17] reported several serious complications: 9 bile duct injuries, 2 intraperitoneal bleedings, 1 hepatic infarction, 1 portal thrombosis, and 1 biliary peritonitis. In the rest of the studies [20-22] no life-threatening complications were noted.

Common minor complications included local moderate pain, fever and increase in blood transaminase levels. In Shibata's series [15], 3/36 patients could not complete MWA therapy due to unbearable pain and they underwent the next session under general anesthesia. Other minor complications included 17 minor and asymptomatic pleural effusions (in nodules located near the diaphragm), 8 minimal subcapsular bleeding cases, treated conservatively, 4 skin burns caused by nodules protruding beyond the liver capsule, 5 ascites cases, 1 liver abscess (treated with percutaneous drainage), 1 cholangitis with intrahepatic bile duct dilatation, 1 subcutaneous abscess accompanied by skin burn treated with percutaneous drainage, and 2 cases of vasovagal reaction.

A large multicenter Italian study, involving 14 centers, that enrolled MWAs in 736 patients with 1,037 lesions, confirmed that microwave procedures are safe with low rate of major complications [23]. In 2011, a systematic review reported the same conclusions on safety of both RFA and MWA, with a low rate of acceptable complications (4.1 and 4.6\% for RFA and MWA techniques, respectively) [24]. 
Table 1 Published data on the use of microwave ablation in the treatment of small hepatocellular carcinomas

\begin{tabular}{|c|c|c|c|c|c|c|}
\hline Reference & $\begin{array}{l}\mathrm{N}^{\circ} \text { pts } / \mathrm{N}^{\circ} \\
\text { tumors }\end{array}$ & Age & $\begin{array}{l}\text { Tumor response: } \\
\text { complete ablation \%/ } \\
\text { local recurrence } \%\end{array}$ & Tumor location & Complications & $\begin{array}{c}\text { Follow up } \\
\text { months/overall } \\
\text { survival } \\
\text { OS \% year }\end{array}$ \\
\hline $\begin{array}{l}\text { Seki, } \\
1999[14]\end{array}$ & $48 / 48$ & 63 & 96 & ns & $\begin{array}{l}\text { Heat sensation and pain in the } \\
\text { upper abdominal region (in } \\
\text { most pts) }\end{array}$ & $\begin{array}{c}32 / \\
78(5 \mathrm{y})\end{array}$ \\
\hline $\begin{array}{l}\text { Shibata, } \\
2002[15]\end{array}$ & $36 / 43$ & 62.5 & 98 & $\begin{array}{l}1 \text { nodule that } \\
\text { has recurrence } \\
\text { was near the } \\
\text { right portal vein }\end{array}$ & $\begin{array}{l}3 / 36 \text { severe pain during } \\
\text { treatment, } 1 / 36 \text { liver abscess, } \\
1 / 36 \text { cholangitis, } 1 / 36 \\
\text { subcutaneous abscess, } 1 / 36 \\
\text { subcapsular hematoma }\end{array}$ & $18 / \mathrm{ns}$ \\
\hline $\begin{array}{l}\text { Liang, } \\
2005[16]\end{array}$ & $83 / 138$ & 54.8 & 135 & $\begin{array}{l}\text { Some nodules } \\
\text { located near the } \\
\text { diaphragm }\end{array}$ & $\begin{array}{l}\text { Local pain, fever, increase in } \\
\text { blood transaminase levels (in } \\
\text { most pts) } \\
2 / 83 \text { skin burns in nodules } \\
\text { protruded beyond the liver } \\
\text { capsule, } 8 / 83 \text { slight subcapsular } \\
\text { bleeding, } 11 / 83 \text { minor pleural } \\
\text { effusion in nodules located } \\
\text { near the diaphragm }\end{array}$ & $\begin{array}{l}31.4 / \\
100(1 \mathrm{y}) \\
93(2 \mathrm{y}) \\
80(3 \mathrm{y}) \\
72(4 \mathrm{y}) \\
62.5(4 \mathrm{y})\end{array}$ \\
\hline $\begin{array}{l}\text { Ohmoto, } \\
2009[17]\end{array}$ & $49 / 56$ & 64 & ns & ns & $\begin{array}{l}49 / 49 \text { pain during treatment } \\
17 / 49 \text { fever, } 11 / 49 \text { pain } \\
\text { after treatment, } 9 / 49 \text { bile } \\
\text { duct injury, } 8 / 49 \text { pleural } \\
\text { effusion, } 5 / 49 \text { ascites, } 4 / 49 \\
\text { skin burns, } 2 / 49 \text { vagovagal } \\
\text { reflex, } 2 / 49 \text { liver abscess, } 2 / 49 \\
\text { intraperitoneal bleeding, } \\
1 / 49 \text { hepatic infarction, } 1 / 49 \\
\text { portal thrombus, } 1 / 49 \text { biliary } \\
\text { peritonitis }\end{array}$ & $\begin{array}{c}34 / \\
89(1 \mathrm{y}) \\
70(2 \mathrm{y}) \\
49(3 \mathrm{y}) \\
39(4 \mathrm{y})\end{array}$ \\
\hline $\begin{array}{l}\text { Ding, } \\
2013[18]\end{array}$ & $113 / 131$ & 59 & $98.5 / 7.3$ & $\begin{array}{l}\text { Tumor adjacent } \\
\text { structures: } \\
\text { Vessels } 7 / 131 \\
\text { Gallbladder } \\
4 / 131 \\
\text { Diaphragm } \\
23 / 131 \\
\text { Bowel } 8 / 131\end{array}$ & $\begin{array}{l}\text { 2/113 liver decompensation } \\
1 / 113 \text { right diaphragmatic } \\
\text { hernia and massive right } \\
\text { pleural effusion }\end{array}$ & $\begin{array}{c}18 / \\
98(1 \mathrm{y}) \\
90.7(2 \mathrm{y}) \\
77.6(3 \mathrm{y}) \\
77.6(4 \mathrm{y})\end{array}$ \\
\hline $\begin{array}{l}\text { Abdelaziz, } \\
2014[19]\end{array}$ & $55 / 55$ & 53.6 & 98.2 & ns & $\begin{array}{l}1 / 55 \text { subcapsular hematoma } \\
1 / 55 \text { skin burn }\end{array}$ & $\begin{array}{l}\mathrm{ns} / 96.4(1 \mathrm{y}) \\
\quad 62(2 \mathrm{y})\end{array}$ \\
\hline
\end{tabular}

Articles and references; number of patients and tumors; age of patients; tumor response (complete ablation-local recurrence); tumor location; complications; follow up (months)/overall survival

No pts, number of patients; pts, patients; OS, overall survival; $y$, years; $n s$, not specified

\section{Discussion}

HCC is increasingly detected at smaller sizes owing to surveillance programs in high-risk patients. When surgical options are precluded, image-guided tumor ablation is recommended as the most appropriate therapeutic choice in terms of tumor local control, safety, and improvement in survival rates [7].

One of the major advantages of the image-guided ablation procedures is the ability to deposit, with a minimally invasive technique, a precise amount of energy in a well-defined region [22]. Among a variety of local ablation therapies, RFA has been the most frequently used worldwide. This ablation modality has gained a wide acceptance as a safe and effective first-line therapeutic option in patients with early HCC not eligible for surgical treatment due to comorbidities; in patients who refuse resection; or when liver function must be preserved [7]. For very early-stage HCC, as staged by BCLC, RFA appears to be equivalent to resection, because of its lower morbidity, shorter hospital stay and greater preservation of hepatic parenchyma [25]. Furthermore, RFA can be used as a component of a multimodal treatment strategy for more 

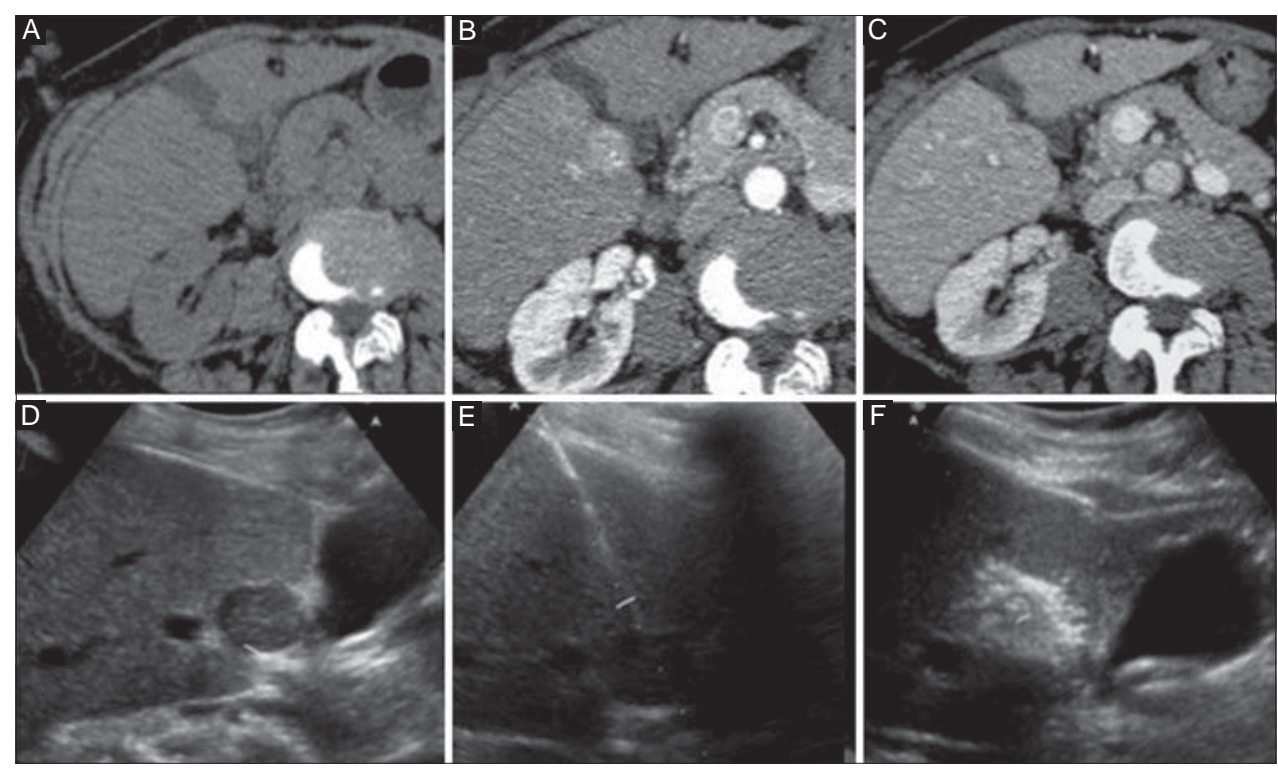

Figure 1 Axial computed tomography images of a small hepatocellular carcinoma localized near gallbladder: (A) Computed tomography scan performed without administration of intravenous contrast media; (B) arterial enhancement of the lesion; and (C) wash-out in the venous phase. (D) Ultrasound examination confirmed the lesion; (E) ultrasound examination performed with the antenna within the lesion; and (F) during the procedure

advanced or recurrent cases, and can play a role as bridging therapy for patients waiting for liver transplantation [26].

In RFA, an electrical current in the radiofrequency range is delivered through a needle electrode. Temperatures range between 60 and $100^{\circ} \mathrm{C}$ and result in almost instant coagulation necrosis [27]. These temperatures are observed near the electrode resulting in a small area of necrosis, with the larger portion of the final ablation zone being attributed to thermal conduction into more peripheral areas around the electrode [28]. Tissue boiling and charring act as electrical insulators and limit the effect of RFA through increased impedance [28]. RFA is also weakened by the heat-sink effect, a phenomenon that occurs when thermal energy is dispersed from the target lesion due to blood flow in the adjacent vessels [8]. Consequently, the shape and size of the ablation zone may be unpredictable and such limitations can lead to inadequate ablation zone and a higher rate of local tumor progression compared with resection. Moreover, the use of RFA is still limited in treating some tumors in high-risk locations [29].

A 'difficult-to-treat' tumor is generally defined as a tumor located within $1 \mathrm{~cm}$ of a vital structure, such as the gastrointestinal tract, gallbladder (Fig. 1), diaphragm, visible intra-hepatic bile duct or vessel (particularly $>3 \mathrm{~mm}$ in diameter) [30,31]. Several strategies have been developed to counter these problems, such as the combined use of RFA and ethanol injection or the use of RFA at maximum radiofrequency power $(>120 \mathrm{~W})$, with more adverse effects (ascites, pleural effusion) [57]. Recently, MWA has emerged as alternative method to RFA, serving as a potentially more powerful technique that can overcome RFA limitations [32]. The two methods differ in their mechanism of action because
RFA uses current whereas MWA uses electromagnetic energy. In contrast to RFA, grounding pads are not needed with MWA, because the completion of an electrical circuit is not required. Therefore, the presence of metallic materials like surgical clips or a pacemaker does not constitute a contraindication and the lack of grounding pads avoids skin burns [33].

Another consequence of the different principle of heat production with MWA is that the time needed for ablation is lower than that required for RFA. The electromagnetic field in MWA creates a rapid and homogeneous heating of the tissue, and subsequently coagulation necrosis; while ionic polarization causes conversion of kinetic energy into heat. The result of this double mechanism of action is the creation of a more homogeneous and easier to predict ablation zone (Fig. 2). The predictability of the ablation area is one of the major advantages of MWA. The faster heating and higher temperatures provided by microwave energy also allow heat-sink effect reduction: this attenuation makes MWA more effective in the treatment of perivascular tumors. Thus, MWA should be preferred for tumors near the hepatic veins and inferior vena cava [34-36]. Moreover MWA emerges as more appropriate for superficial lesions [35].

The results regarding comparison between survival, local recurrence and complication rates of MWA and RFA are still controversial. Overall, the published studies support the comparability of the two methods $[37,38]$. RFA is the most studied and affirmed technique, though MWA is currently considered a viable alternative, as demonstrated by our results. We reported a mean initial complete response of $95 \%$ for RFA and $98 \%$ for MWA. The survival rates were similar for MWA and RFA groups: in the range of $59-100 \%$ for RFA and of 

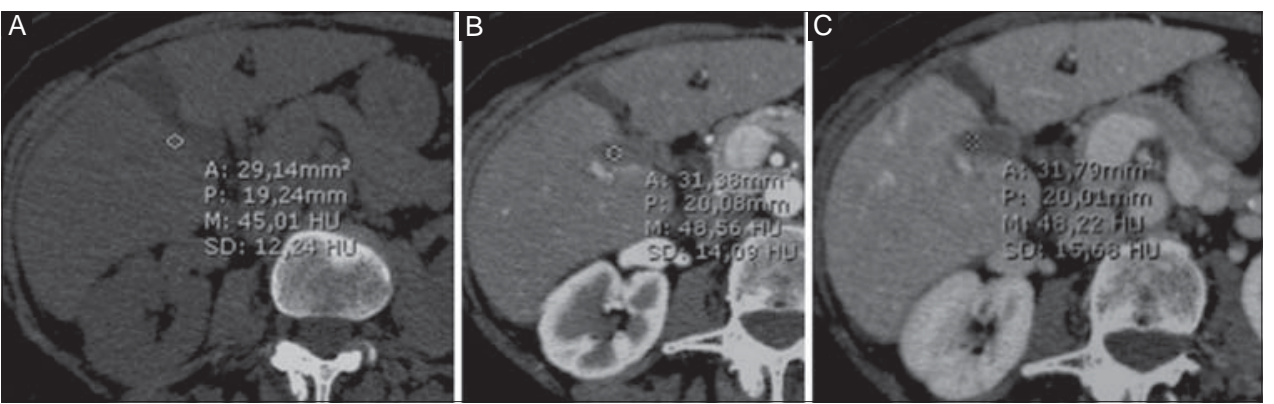

Figure 2 Computed tomography scan performed 6 months after the treatment showed a hypodense area without any enhancement (complete necrosis): (A) unenhanced; (B) arterial; and (C) venous, acquisitions

$89-100 \%$ for MWA at 1 year and in the range of $41-92 \%$ for RFA and of $49-80 \%$ for MWA at 3 years.

Recently, Shi et al reported that for solitary $\mathrm{HCC} \leq 3 \mathrm{~cm}$, MWA is as effective as surgical resection [39]. In a recent study, Abdelaziz [19] determined the safety of MWA for earlystage HCC lesions, with a low rate of minor complications: in particular, in the RFA group there were $11.1 \%$ procedurerelated complications and in the MWA group only 3.2\% of complications were reported. Complications reported after MWA do not differ from those after RFA, both are mainly based on heat damage. Livraghi et al [23] in a multicenter study confirmed the safety of MWA, reporting 0\% mortality, 2.9\% major complications, and 7.2\% minor complications. Reported peri-procedural mortality rate was $<0.01 \%$, thus the safety of MWA was established.

A recent retrospective comparative evaluation of RFA and MWA therapeutic effects in treating patients with HCC showed no significant differences in the treatment of HCCs regarding complete response, rates of residual untreated disease, recurrence rates, and survival rates [22]. Emerging data suggest that, although MWA is a new method and the cumulative reported experience is limited, promising results were obtained in cases in which RFA presented limitations. Moreover, recently MWA of small HCCs was able to provide similar long-term outcomes compared to surgery [39].

\section{Concluding remarks}

On the basis of the results reported and of the proven advantages of microwave technique (lower procedural pain, shorter time of procedure and reduction of heat sink effect), thermal ablation using microwave may be considered a valid alternative for small lesions located near vessels (diameter $>3 \mathrm{~mm}$ ), near gallbladder or in subglissonian area. A randomized trial is the only method to confirm this data. Moreover, a prospective randomized study should ideally be conducted to compare long-term outcomes in patients treated with MWA and with surgery. Unfortunately, this study would be difficult to carry out because HCC appears most commonly in cirrhotic patients, not usually considered ideal candidates for surgery.

\section{References}

1. Bruix J, Sherman M; AASLD Practice Guideline, Management of hepatocellular carcinoma: an update. Hepatology 2011;53:1020-1022.

2. EASL-EORTC clinical practice guidelines: management of hepatocellular carcinoma. J Hepatol 2012;56:908-943.

3. Bruix J, Sherman M; Practice Guidelines Committee, American Association for the Study of Liver Diseases. Management of hepatocellular carcinoma. Hepatology 2005;42:1208-1236.

4. Tan CH, Low SC, Thng CH. APASL and AASLD consensus guidelines on imaging diagnosis of hepatocellular carcinoma: a review. Int J Hepatol 2011;2011:1-11.

5. Minami Y, Kudo M. Radiofrequency ablation of hepatocellular carcinoma: Current status. World J Radiol 2010;2:417-424.

6. Livraghi T, Solbiati L, Meloni MF, et al. Treatment of focal liver tumors with percutaneous radio-frequency ablation: complications encountered in a multicenter study. Radiology 2003;226:441-451.

7. Thandassery RB, Goenka U, Goenka MK. Role of local ablative therapy for hepatocellular carcinoma. J Clin Exp Hepatol 2014;4:104-111.

8. Lu DS, Raman SS, Limanond P, et al. Influence of large peritumoral vessels on outcome of radiofrequency ablation of liver tumors. $J$ Vasc Interv Radiol 2003;14:1267-1274.

9. Simon CJ, Dupuy DE, Mayo-Smith WW, et al. Microwave ablation: principles and applications. Radiographics 2005;1:S69-S83.

10. Carrafiello G, Laganà D, Mangini $M$, et al. Microwave tumors ablation: principles, clinical applications and review of preliminary experiences. Int J Surg 2008; 1:S65-S69.

11. Wright SA, Sampson LA, Warner TF, et al. Radiofrequency versus microwave ablation in a hepatic porcine model. Radiology 2005;236:132-139.

12. Seki T, Wakabayashi M, Nakagawa $T$, et al. Ultrasonically guided percutaneous microwave coagulation therapy for small hepatocellular carcinoma. Cancer 1994;74:817-825.

13. Wang ZL, Liang P, Dong BW, et al. Prognostic factors and recurrence of small hepatocellular carcinoma after hepatic resection or microwave ablation: a retrospective study. J Gastrointest Surg 2008;2:327-337.

14. Seki T, Wakabayashi M, Imamura M, et al. Percutaneous microwave coagulation therapy for patients with small hepatocellular carcinoma: comparison with percutaneous ethanol injection therapy. Cancer 1999;85:1694-1702.

15. Shibata T, Iimuro Y, Yamamoto Y, et al. Small hepatocellular carcinoma: comparison of radio-frequency ablation and percutaneous microwave coagulation therapy. Radiology 2002;223:331-337.

16. Liang P, Dong B, Yu X, et al. Prognostic factors for survival in patients with hepatocellular carcinoma after percutaneous 
microwave ablation. Radiology 2005;235:299-307.

17. Ohmoto K, Yoshioka N, Tomiyama Y, et al. Comparison of therapeutic effects between radiofrequency ablation and percutaneous microwave coagulation therapy for small hepatocellular carcinomas. $J$ Gastroenterol Hepatol 2009;24:223-227.

18. Ding J, Jing X, Liu J, et al. Comparison of two different thermal techniques for the treatment of hepatocellular carcinoma. Eur $J$ Radiol 2013;82:1379-1384.

19. Abdelaziz A, Elbaz T, Shousha HI, et al. Efficacy and survival analysis of percutaneous radiofrequency versus microwave ablation for hepatocellular carcinoma: an Egyptian multidisciplinary clinic experience. Surg Endosc 2014;28:3429-3434.

20. Lu MD, Chen JW, Xie XY, et al. Hepatocellular carcinoma: US guided percutaneous microwave coagulation therapy. Radiology 2001;221:167-172.

21. Xu HX, Xie XY, Lu MD, et al. Ultrasound-guided percutaneous thermal ablation of hepatocellular carcinoma using microwave and radiofrequency ablation. Clin Radiol 2004;59:53-61.

22. Vogl TJ, Farshid P, Naguib NN, et al. Ablation therapy of hepatocellular carcinoma: a comparative study between radiofrequency and microwave ablation. Abdom Imaging 2015;40: 1829-1837.

23. Livraghi T, Meloni F, Solbiati L, et al. Collaborative Italian Group using AMICA system. Complications of microwave ablation for liver tumors: results of a multicenter study. Cardiovasc Intervent Radiol 2012;35:868-874.

24. Bertot LC, Sato M, Tateishi R, et al. Mortality and complication rates of percutaneous ablative techniques for the treatment of liver tumors: a systematic review. Eur Radiol 2011;21:2584-2596.

25. Livraghi T, Meloni F, Di Stasi M, et al. Sustained complete response and complications rates after radiofrequency ablation of very early hepatocellular carcinoma in cirrhosis: is resection still the treatment of choice? Hepatology 2008;47:82-89.

26. Kim YS, Lim HK, Rhim H, et al. Ablation of hepatocellular carcinoma. Best Pract Res Clin Gastroenterol 2014;28:897-908.

27. Gervais DA, Arellano RS. Percutaneous tumor ablation for hepatocellular carcinoma. AJR 2011;197:789-794.

28. Brace CL. Radiofrequency and microwave ablation of the liver, lung, kidney, and bone: what are the differences? Curr Probl Diagn Radiol 2009;38:135-143.

29. Karaman B, Battal B, Sari S, et al. Hepatocellular carcinoma review: current treatment, and evidence-based medicine. World $J$ Gastroenterol 2014;20:18059-18060.

30. Lin SM. Local Ablation for Hepatocellular Carcinoma in Taiwan. Liver Cancer 2013;2:73-83.

31. Lu DS, Raman SS, Vodopich DJ, et al. Effect of vessel size on creation of hepatic radiofrequency lesions in pigs: assessment of the 'heat sink' effect. AJR 2002;178:47-51.

32. Simo KA, Sereika SE, Newton KN, et al. Laparoscopic assisted microwave ablation for hepatocellular carcinoma: safety and efficacy in comparison with radiofrequency ablation. J Surg Oncol 2011;104:822-829.

33. Lubner MG, Brace CL, Hinshaw JL, et al. Microwave tumor ablation: mechanism of action, clinical results, and devices. J Vasc Interv Radiol 2010;21:S192-S203.

34. Yu NC, Raman SS, Kim YJ, et al. Microwave liver ablation: influence of hepatic vein size on heat sink effect in a porcine model. J Vasc Interv Radiol 2008;19:1087-1092.

35. Liang P, Wang Y. Microwave ablation of hepatocellular carcinoma. Oncology 2007;72:S124-S131.

36. Ierardi AM, Mangano A, Floridi C, et al. A new system of microwave ablation at $2450 \mathrm{MHz}$ : preliminary experience. Updates Surg 2015;67:39-45.

37. Tomesi P, Di Vece F, Sartori S. Resection vs thermal ablation of small hepatocellular carcinoma: what's the first choice? World $J$ Radiol 2013;5:1-4.

38. Poulou LS, Botsa E, Thanou I, et al. Percutaneous microwave ablation vs radiofrequency ablation in the treatment oh hepatocellular carcinoma. World J Hepatol 2015;7:1054-1063.

39. Shi J, Sun Q, Wang Y, et al. Comparison of microwave ablation and surgical resection for treatment of hepatocellular carcinomas conforming to Milan criteria. J Gastroenterol Hepatol 2014;29:1500-1507. 